\title{
Ultrasound for Critical Care Physicians: Complication of a Distant Malignancy
}

\author{
S. Cham Sante M.D. ${ }^{1}$ \\ Michel Boivin M.D. ${ }^{2}$ \\ Department of Emergency Medicine ${ }^{1}$ \\ Division of Pulmonary, Critical care and Sleep Medicine ${ }^{2}$ \\ University of New Mexico School of Medicine \\ Albuquerque, NM USA
}

An 82-year-old woman with prior medical history of stage IV colon cancer and chronic obstructive pulmonary disease presented to the medical intensive care unit with newly diagnosed community acquired pneumonia and acute kidney injury. The patient presented with acute onset of shortness of breath, nausea, generalized weakness, bilateral lower extremity swelling and decreased urine output. She was transferred for short term dialysis in the setting of multiple electrolyte abnormalities, including hyperkalemia of $6.4 \mathrm{mmol} / \mathrm{l}$, as well as a creatinine of $6.5 \mathrm{mg} / \mathrm{dl}$. The following imaging of the right internal jugular vein was performed with ultrasound during preparation for placement of a temporary triple lumen hemodialysis catheter.

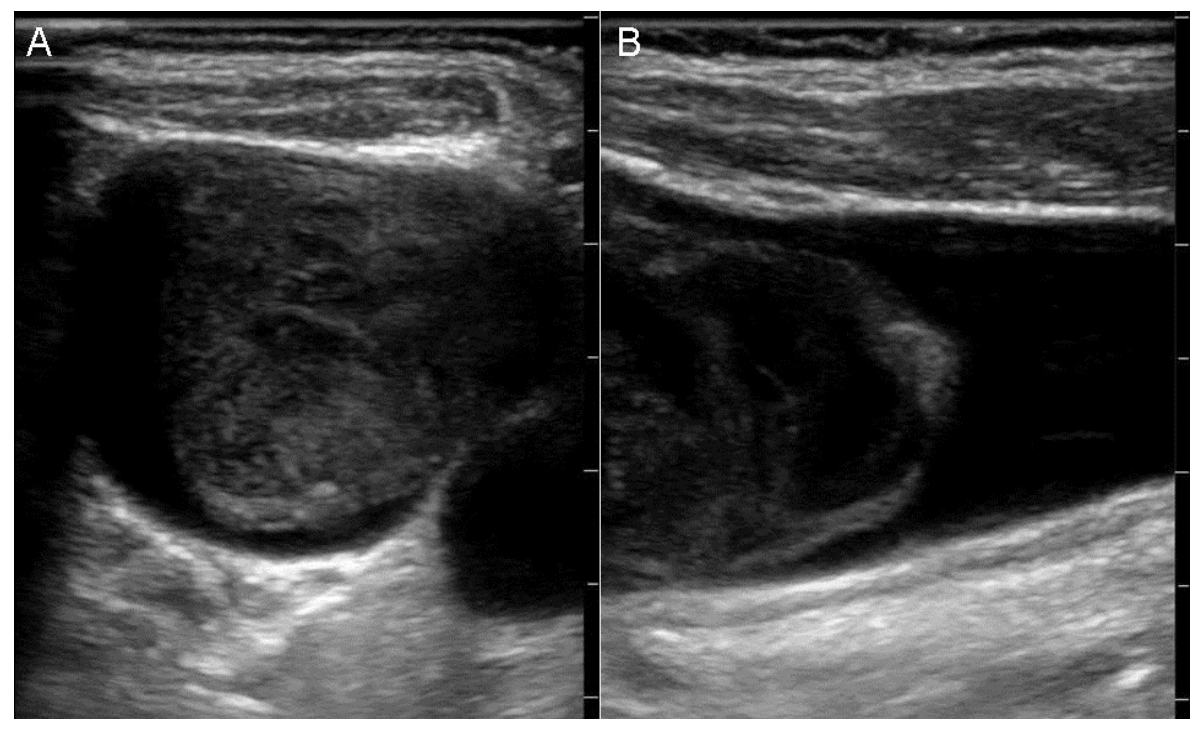

Figure 1. Panel A: Transverse ultrasound image of the right neck. Panel B: Longitudinal ultrasound image of the right neck, centered on the internal jugular vein.

Based on the above imaging what would be the best location to place the dialysis catheter?

1. Left internal jugular vein

2. Right femoral vein

3. Right internal jugular vein

4. Right subclavian vein 


\section{Correct! \\ 2. Right femoral vein}

A large echogenic mass was seen occluding approximately 90 percent of the right internal jugular vein, extending cranially and caudally throughout the neck (Figure 2).

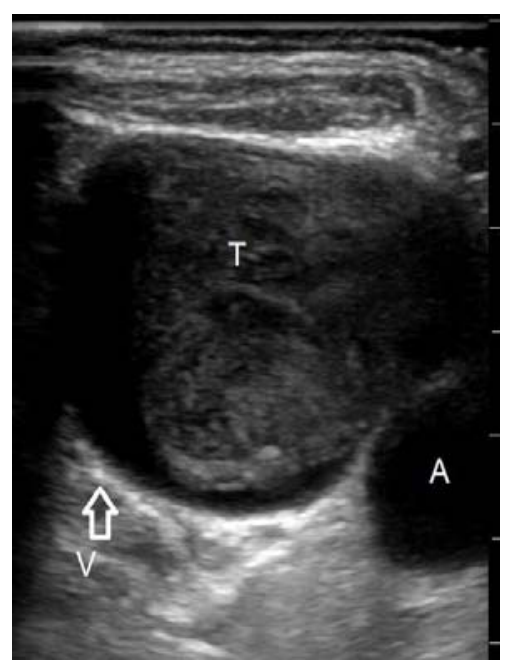

Figure 2. Transverse ultrasound image of the right neck labeled demonstrating the internal jugular vein $(V)$, thrombus $(T)$, and carotid artery $(A)$.

This echogenic mass represented a thrombus which formed in an internal jugular vein naive to previous central line placement or cannulation. The decision was made to place the hemodialysis catheter in the right femoral vein, which occurred successfully without complication. The contralateral internal jugular vein should be avoided in the setting of an internal jugular thrombosis so as to avoid bilateral impairment of venous return. Subclavian dialysis catheters are often avoided due to the risk of stenosis. The patient was started on hemodialysis which corrected her electrolyte abnormalities and her kidney function began to trend back to baseline. Unfortunately, renal ultrasound demonstrated that the patient's acute kidney injury was found to be secondary to obstruction by large abdominal masses from her gastrointestinal carcinoma. The patient opted not to have a nephrostomy tube placed, instead deciding to stop hemodialysis and return home on hospice care.

\section{Discussion}

Internal jugular venous thrombosis in a vessel without previous cannulation or central line placement is an uncommon occurrence with the potential for serious complications such as pulmonary embolus, sepsis or cerebral edema. Several studies have looked at characteristics that predispose patients to internal jugular vein thrombosis, demonstrating that older patients, female gender and ovarian hyperstimulation syndrome are significantly associated risk factors (1). Internal jugular thrombosis 
resulting from hypercoagulability secondary to distant malignancies has also been described in the literature (2-7). This case study adds to the body of evidence demonstrating an association between internal venous thrombosis and distant underlying malignancy. Such an association has implications to both potentially aid in the detection of undiagnosed occult malignancies in patients found to have spontaneous internal jugular thrombosis, as well as for vigilant surveillance for complications resulting from predisposition to internal jugular vein thrombosis in patients with known malignancy. The above case also demonstrates the importance of routine ultrasound examination of the proposed site of central venous catheterization.

\section{References}

1. Gbaguidi X, Janvresse A, Benichou J, Cailleux N, Levesque H, Marie I. Internal jugular vein thrombosis: outcome and risk factors. QJM. 2011 Mar;104(3):209-19. [CrossRef] [PubMed]

2. Rayson D, Ingle JN, Pruthi RK. Thrombosis of the internal jugular vein: a rare manifestation of the hypercoagulability of malignancy. Cancer Invest. 1998;16(5):319-21. [CrossRef] [PubMed]

3. Langlieb AM, Dunton CJ, Carlson JA Jr. Spontaneous internal jugular vein thrombosis associated with leiomyosarcoma of the omentum. Gynecol Oncol. 1992 Oct;47(1):125-6. [CrossRef] [PubMed]

4. Van den Noortgate N, Michielsen W, Afschrift M, Van Belle S. Spontaneous internal jugular vein thrombosis: primary manifestation of a colorectal adenocarcinoma in a very old woman. Acta Clin Belg. 2000 Mar-Apr;55(2):94-6. [PubMed]

5. Unsal EE, Karaca C, Ensarí S. Spontaneous internal jugular vein thrombosis associated with distant malignancies. Eur Arch Otorhinolaryngol. 2003 Jan;260(1):39-41. [PubMed]

6. Pata YS, Unal M, Gülhan S. Internal jugular vein thrombosis due to distant malignancies: two case reports and literature review. J Laryngol Otol. 2008 Mar;122(3):318-20. [CrossRef] [PubMed]

7. Carrington BM, Adams JE . Jugular vein thrombosis associated with distant malignancy. Postgrad Med J. 1988 Jun;64(752):455-8. [CrossRef] [PubMed] 